\title{
Long-term results of randomized studies on the use of a gentamicin-collagen sponge in rectal cancer - depending on the length of time between the completion of radiotherapy and the surgery
}

\author{
Adam Dmitruk, Tomasz Olesiński, Piotr Hevelke, Łukasz Zyskowski, Andrzej Rutkowski
}

Introduction. Two randomized studies on the use of a gentamicin-collagen sponge (GRM01/1997 and GRM02/2007) in rectal cancer surgery showed a statistically significant decrease in the rate of distant metastases in the experimental group and a similar rate of local recurrences. The objective of the presented study was a retrospective evaluation of the effect of the GRM use on the observed rate of generalized recurrences, disease-free survival (DFS), overall survival (OS) and cancer-specific survival (CSS) - depending on the length of the interval between radiotherapy and surgery.

Materials and methods. The study comprised 239 patients, included previously into randomized studies, in whom the $5 \times 5$ Gy radiotherapy was used. In 204 people, the surgery was made within 7 days of the completion of radiotherapy (group A). The remaining group of 35 patients were operated on after 4-8 weeks (group B). The follow-up period was 5 years. The statistical analysis was made with the Kaplan-Meier test. The value of $a=0.05$ was degfined as the threshold of statistical significance.

Results. In both groups, there were no statistical differences between the patients operated on with the use of GRM and those operated on without the use of GRM. The analysis took into consideration the most significant parameters, which could affect the oncological results, (ypTNM, lympho-vascular invasion (LVI), blood vessel invasion (BVI). In group A, the use of GRM was connected with a lower rate of metachronic distant metastases ( $p=0.002 ; \mathrm{RR} 0.41 ; 95 \% \mathrm{Cl}[0.24-0.72]$ ), the prolongation of DFS ( $p=0.008$; HR 2.16; 95\% Cl [1.20-3.83]) and of CSS ( $p=0.010 ; \mathrm{HR} 2.37 ; 95 \% \mathrm{Cl}$ [1.20-4. 67]). No such relationships were observed in group B.

Conclusions. The use of GRM decreases the risk of distant metastases and has an influence on the prolongation of recurrence free survival, but only when surgery is carried out within 7 days of the completion of irradiation.

Key words: rectal cancer, radiotherapy, gentamicin-collagen sponge

\section{Introduction}

The results of two randomized clinical studies (GRM01/1997 and GRM02/2007) showed that intraoperative use of a gen- tamicin-collagen sponge in rectal cancer patients, undergoing preoperative radiotherapy, followed by radical tumour resection, decreases the risk of distant metastases [1, 2].

\section{How to cite:}

Dmitruk A, Olesiński T, Hevelke P, Zyskowski Ł, Rutkowski A. Long-term results of randomized studies on the use of a gentamicin-collagen sponge in rectal cancerdepending on the length of time between the completion of radiotherapy and the surgery. NOWOTWORY J Oncol 2021; 71: 139-145. 
The objective of the first study (Nowacki et al.) [1] was to determine the effect of GRM on the risk of post-operative complications and oncological results. The surprising results of the 3-year long-term follow-up, showed a significantly lower rate of distant metastases in the group of patients operated on with the use of GRM inspired another study with the objective to confirm the previous results (Rutkowski et al.) [2]. This time, the main objective of the project was to confirm the anti-cancer properties of GRM with regards to a reduction of generalized relapse. The study confirmed earlier observations: in the patient group with GRM, distant metastases occurred twice as rarely than in the control group (8.6\% vs. $23.5 \%$; HR 2.4; 95\% Cl: 1.1-5.5; $p=0.005$ ).

Still, the mechanism of action of the studied medicinal product, which led to a decrease in the rate of generalized recurrence, is unknown. One of the considered hypotheses is the correlation between the antibiotic (GRM), which has a local effect on the irradiated area and the previously used ionizing irradiation, with respect to the activation of immunological mechanisms. Radiotherapy, by means of affecting the micro-environment of the tumour, creates the potential to reverse immunosuppressive conditions present in cancer [3]. An important role here is played by a fractional dose of radiotherapy [4]. The objective of the presented study was to evaluate how the interval between the last fractional dose of radiotherapy and the surgery, affects oncological outcomes.

\section{Materials and methods}

The analysis concerned the data of the patients who participated in two randomized studies, completed and published. The criteria of participation were described before [1, 2]. Both studies concerned patients with rectal primary adenocarcinoma. The randomization was made with a 1:1 proportion, and the study group were those patients who, after resection of the tumour with mesorectum, had a GRM implanted into the pelvis. The same agent was used in both studies. The clinical stage of the cancer was evaluated on the basis of the computed tomography (CT) of the abdominal cavity and pelvis with the contrast medium administered intravascularly. In the period when the clinical material was collected (1997-1999 and 2008-2011), magnetic resonance imaging (MRI) of the pelvis was not a diagnostic standard in the research centre. Qualification for the treatment was made on the basis of the multidisciplinary team's decision. Radiotherapy with high fractional doses (5 × 5 Gy) was applied in the case of resectable tumours with cT3-4 NO-2 M0 stage.

The treatment standard was a radical resection within 7 days of the completion of radiotherapy. The interval was prolonged only when there were medical contraindications for the surgery at the designed moment (e.g. an active infection, exacerbation of non-cancer related comorbidities). The surgeries were performed by one team of experienced sur- geons. The operative technique was total mesorectum excision (TME). All the perioperative and post-operative complications, occurring within 30 days of surgery, were carefully reported. The pathomorphological assessment comprised:

- histological type of the tumour,

- TNM stage,

- $\quad$ radicality of the resection ( $R$ feature).

Additionally, the second study also assessed:

- the stage of the primary tumour (ypT),

- the condition of the regional lymph nodes (ypN),

- tumour differentiation (G feature),

- cancer invasion of lymphatic and/or blood vessels,

- radicality of the mesorectum resection,

- the length of the resection margin.

The data from the pathomorphological protocol, which were not routinely specified in the first study (Nowacki et al. [1]), were completed retrospectively. Patients with the third TNM stage of the disease also underwent adjuvant treatment (chemotherapy: $5 \mathrm{FU}+\mathrm{LV}$, and, in the second study also OX + $5 \mathrm{FU}+\mathrm{LV}$ ). The long-term observation consisted of an evaluation of the clinical condition with the CEA determination: - every 3 months - for the first 2 years after the surgery,

- then - every 6 months - up to 5 years after the surgery. Imaging diagnostics of the abdominal cavity were performed routinely, once per year, or more frequently in the case when a relapse was suspected. A colonoscopy was a standard assessment in the third and fifth year postoperatively. The criterion for diagnosing local recurrence was the presence of a tumor in the pelvis or within the anastomosis. Distant metastases were defined as the presence of tumors in any other location. If there was any doubt concerning the character of the observed lesions, then a biopsy and microscope verification were recommended.

The selection criteria for this study are presented in figure 1. Patients undergoing preoperative radio-chemotherapy were excluded from the study as in the study period, this method of treatment was applied solely in patients with a primarily non-resectable tumour. Depending on the length of the interval between the completion of the irradiation and the surgery, two groups of patients were distinguished:

- A: a short interval between the end of radiotherapy and surgery (the surgery was performed within 0-7 days from the completion of radiotherapy) - 204 patients,

- B: a long interval between the end of radiotherapy and surgery (the surgery was performed within 4-8 weeks from the completion of radiotherapy) - 35 patients.

In both groups, instead of the randomization result, the clinical data concerning the actual use of GRM (or not) were taken into consideration. The comparative characteristics of both groups are presented in table I. The grade of the disease, determined on the basis of the histopathological assessment of the resected post-operative material in patients in group $B$ was lower than in group A ( $p=0.005)$. In $22(63 \%)$ operated 


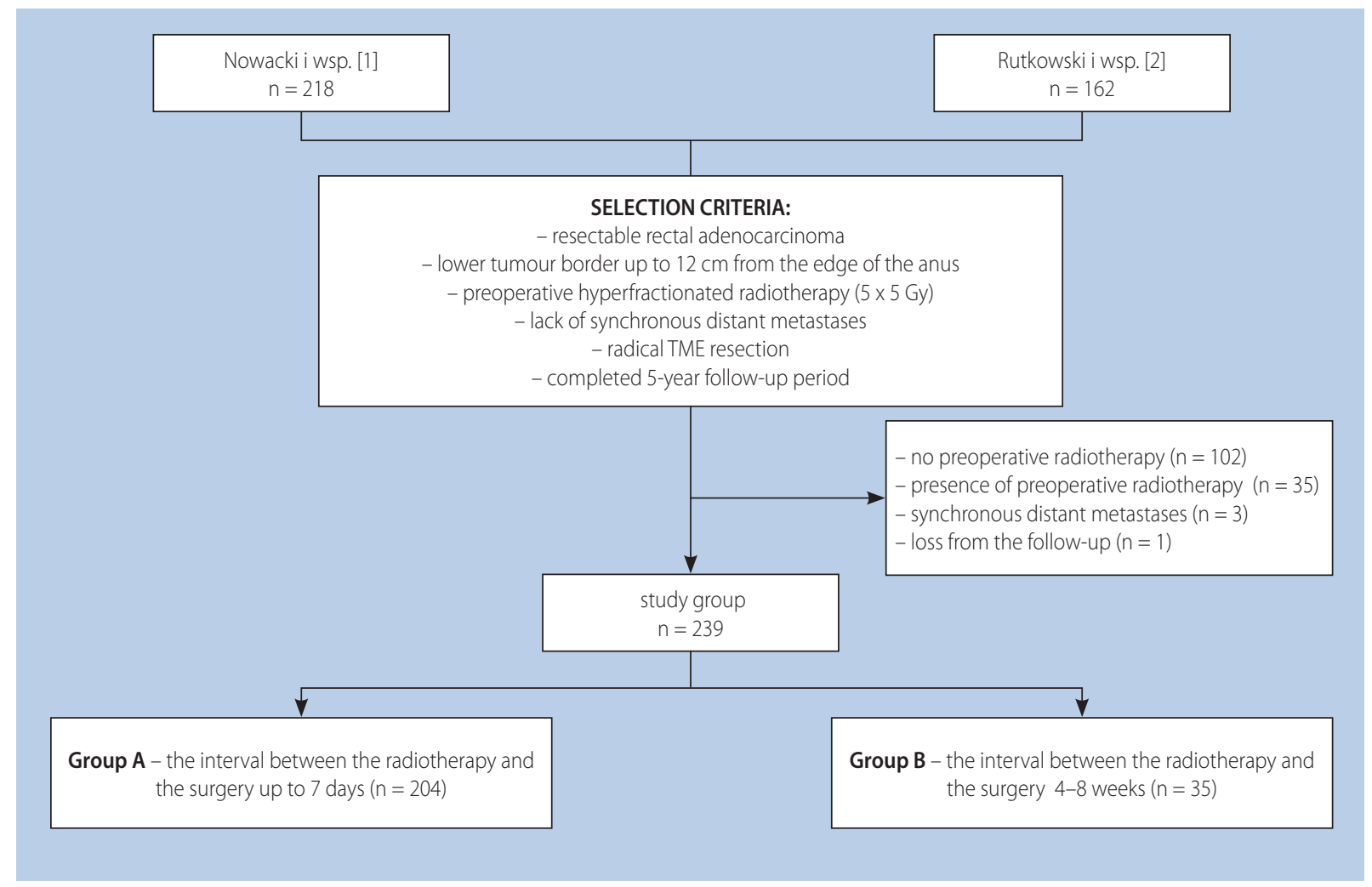

Figure 1. Patient selection

Table I. Comparative characteristics of the patients within the groups selected on the basis of the length of the interval between the completion of hyperfractionated radiotherapy and the surgery

\begin{tabular}{|c|c|c|c|c|}
\hline Patients' characteristics & & Group A n (\%) & Group B n (\%) & p \\
\hline sex: & $\begin{array}{l}\text {. men } \\
\text { - women }\end{array}$ & $\begin{array}{l}134(66) \\
70(34)\end{array}$ & $\begin{array}{l}24(69) \\
11(31)\end{array}$ & 0.739 \\
\hline age: & - median [range] & $63[25-84]$ & $62[38-81]$ & 0.941 \\
\hline the distance between the tumour and the anus $(\mathrm{cm})$ & - median [range] & $5[0-12]$ & $5[1-10]$ & 0.878 \\
\hline surgery type: & $\begin{array}{l}\text { - } L A R \\
\text { - } A R \\
\text { - } A S A R \\
\text { - Hrtm. }\end{array}$ & $\begin{array}{c}87(43) \\
39(19) \\
60(29) \\
18(9)\end{array}$ & $\begin{array}{l}23(66) \\
5(14) \\
5(14) \\
2(6)\end{array}$ & 0.094 \\
\hline the use of GRM: & $\begin{array}{l}\text { - yes } \\
\text { - no }\end{array}$ & $\begin{array}{l}102(50) \\
102(50)\end{array}$ & $\begin{array}{l}19(54) \\
16(46)\end{array}$ & 0.716 \\
\hline post-operative complications: & $\begin{array}{l}\text { - yes } \\
\text { - no }\end{array}$ & $\begin{array}{l}62(30) \\
142(70)\end{array}$ & $\begin{array}{l}11(31) \\
24(69)\end{array}$ & 0.902 \\
\hline radicality of the resection: & $\begin{array}{l}\text { - } R 0 \\
\text { - } R 1\end{array}$ & $\begin{array}{c}200(98) \\
4(2)\end{array}$ & $\begin{array}{c}35(100) \\
0(-)\end{array}$ & 1.000 \\
\hline ypTNM: & $\begin{array}{l}\text { - } \text { stage } 0 \text { (CR) } \\
\text { - } \text { stage I } \\
\text { - } \text { stage II } \\
\text { - } \text { stage III }\end{array}$ & $\begin{array}{l}1(0,5) \\
43(21) \\
66(32) \\
94(46)\end{array}$ & $\begin{array}{c}3(9) \\
12(34) \\
10(29) \\
10(29)\end{array}$ & 0.005 \\
\hline surgical margin: & 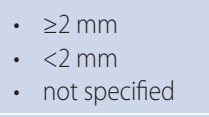 & $\begin{array}{c}125(93) \\
9(7) \\
70(-)\end{array}$ & $\begin{array}{c}27(96) \\
1(4) \\
7(-)\end{array}$ & 0.196 \\
\hline lymphatic vessels invasion: & $\begin{array}{l}\text { - yes } \\
\text { - no } \\
\text { - } \text { not specified }\end{array}$ & $\begin{array}{c}53(35) \\
97(66) \\
54(-)\end{array}$ & $\begin{array}{c}6(22) \\
21(78) \\
8(-)\end{array}$ & 0.267 \\
\hline blood vessels invasion: & $\begin{array}{l}\cdot \text { yes } \\
\cdot \text { no } \\
\text {. not specified }\end{array}$ & $\begin{array}{l}51(35) \\
92(64) \\
61(-)\end{array}$ & $\begin{array}{c}7(26) \\
20(74) \\
8(-)\end{array}$ & 0.328 \\
\hline
\end{tabular}

GRM - gentamicin-collagen sponge; LAR - low anterior resection; AR - anterior resection; ASAR - abdominosacral amputation of the rectum; Hrtm. - Hartmann procedure 
patients, after a long break, the grade was determined to be I or II. In 3 patients (9\%), a complete pathomorphological remission was observed, which may be related to cancer remission observed after radiotherapy.

The statistical analysis was made on the basis of actual use, or not, of GRM (per-protocol analysis) made in two subgroups of patients selected on the basis of the interval between radiotherapy and surgery. The differences between the categorised variables were assessed with the use of $x^{2}$ test or Fisher's exact test. Continuous variables were compared with the Mann-Whitney U-test. Overall survival (OS), disease free survival (DFS) and cancer specific survival (CCS) were assessed with the Kaplan-Meier method and compared with the long-rank test. The level of statistical significance was established in all the tests on the level of $a=0.05$.

\section{Results}

GRM was applied in 102 (50\%) patients in group A and in 19 (54\%) in group B. In both groups, there were no statistically significant differences between the operated patients with the use of GRM and the operated patients without the use of GRM. The comparison took into consideration the most important parameters which might affect the oncological results, such as:

- ypTNM cancer stage (group A: $p=0.207$; group $B: p=0.401$ ),

- Iympho-vascular invasion (LVI) (group A: $p=0.865$; group B: $p=0.182$,

- blood vessel invasion (BVI) (group A: $p=0.221$; group B: $\mathrm{p}=0.408$ ) (tab. II).

Metachronic distant metastases were observed in 48 (23.5\%) patients in group A and in $3(8.6 \%)$ in group B ( $p=0.07$;

Table II. Patients' characteristics, taking into consideration the use of gentamicin-collagen sponge (GRM)

\begin{tabular}{|c|c|c|c|c|c|c|}
\hline \multirow[t]{2}{*}{ Patients' characteristics } & \multicolumn{2}{|c|}{ Group A } & \multirow[b]{2}{*}{$\mathbf{p}$} & \multicolumn{2}{|c|}{ Group B } & \multirow[b]{2}{*}{$p$} \\
\hline & $\begin{array}{c}\text { GRM (+) } \\
\text { n (\%) }\end{array}$ & $\begin{array}{c}\text { GRM (-) } \\
\text { n (\%) }\end{array}$ & & $\begin{array}{c}\text { GRM (+) } \\
\text { n (\%) }\end{array}$ & $\begin{array}{c}\text { GRM (-) } \\
\text { n (\%) }\end{array}$ & \\
\hline $\begin{array}{l}\text { sex: } \\
\text { - men } \\
\text { - women }\end{array}$ & $\begin{array}{l}69(68) \\
33(32)\end{array}$ & $\begin{array}{l}65(64) \\
37(36)\end{array}$ & 0.658 & $\begin{array}{r}12(63) \\
7(37)\end{array}$ & $\begin{array}{r}12(75) \\
4(25)\end{array}$ & 0.493 \\
\hline $\begin{array}{l}\text { age: } \\
\cdot \text { median } \\
\text { [range] }\end{array}$ & $\begin{array}{c}63 \\
{[30-84]}\end{array}$ & $\begin{array}{c}62 \\
{[25-83]}\end{array}$ & 0.638 & $\begin{array}{c}60 \\
{[38-81]}\end{array}$ & $\begin{array}{c}70 \\
{[52-75]}\end{array}$ & 0.159 \\
\hline $\begin{array}{l}\text { the distance between the tumour and the anus }(\mathrm{cm}) \\
\text { - median } \\
\text { [range] }\end{array}$ & $\begin{array}{c}6 \\
{[0,5-12]}\end{array}$ & $\begin{array}{c}5 \\
{[0-12]}\end{array}$ & 0.159 & $\begin{array}{c}5 \\
{[1-10]}\end{array}$ & $\begin{array}{c}6 \\
{[1-8]}\end{array}$ & 0.382 \\
\hline $\begin{array}{l}\text { surgery type: } \\
\text { - } \text { LAR } \\
\text { - } \text { AR } \\
\text { - } \text { ASAR } \\
\text { - Hrtm. }\end{array}$ & $\begin{array}{l}42(41) \\
23(23) \\
29(28) \\
8(8)\end{array}$ & $\begin{array}{l}45(44) \\
16(16) \\
31(30) \\
10(10)\end{array}$ & 0.648 & $\begin{array}{c}12(63) \\
3(16) \\
3(16) \\
1(5)\end{array}$ & $\begin{array}{l}11(68) \\
2(13) \\
2(13) \\
1(6)\end{array}$ & 1.000 \\
\hline $\begin{array}{l}\text { post-operative complications: } \\
\text { - yes } \\
\text { - no }\end{array}$ & $\begin{array}{l}27(26) \\
75(74)\end{array}$ & $\begin{array}{l}35(34) \\
67(66)\end{array}$ & 0.287 & $\begin{array}{r}5(26) \\
14(74)\end{array}$ & $\begin{array}{r}6(37) \\
10(63)\end{array}$ & 0.716 \\
\hline $\begin{array}{l}\text { radicality of the resection: } \\
\text { - } \text { R0 } \\
\text { - } \text { R1 }\end{array}$ & $\begin{array}{c}99(97) \\
3(3)\end{array}$ & $\begin{array}{c}101(99) \\
1(1)\end{array}$ & 0.621 & $\begin{array}{c}19(100) \\
0(0)\end{array}$ & $\begin{array}{c}16(100) \\
0(0)\end{array}$ & 1.000 \\
\hline 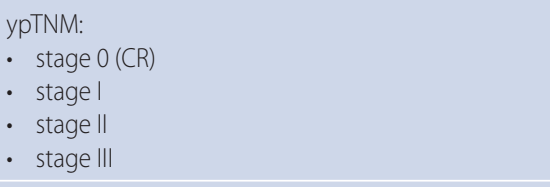 & $\begin{array}{c}0(0) \\
25(25) \\
36(35) \\
41(40)\end{array}$ & $\begin{array}{c}1(1) \\
18(18) \\
30(29) \\
53(52)\end{array}$ & 0.207 & $\begin{array}{l}3(16) \\
6(32) \\
4(20) \\
6(32)\end{array}$ & $\begin{array}{l}0(0) \\
6(37) \\
6(37) \\
4(26)\end{array}$ & 0.401 \\
\hline $\begin{array}{l}\text { surgical margin: } \\
\cdot \quad \geq 2 \mathrm{~mm} \\
\cdot \quad<2 \mathrm{~mm} \\
\cdot \text { - not specified }\end{array}$ & $\begin{array}{l}61(92) \\
5(8) \\
36(-)\end{array}$ & $\begin{array}{c}64(94) \\
4(6) \\
34(-)\end{array}$ & 0.742 & $\begin{array}{c}14(93) \\
1(7) \\
4(-)\end{array}$ & $\begin{array}{c}13(100) \\
0(0) \\
3(-)\end{array}$ & 1.000 \\
\hline $\begin{array}{l}\text { lymphatic vessels invasion: } \\
\text { - yes } \\
\text { - no } \\
\text { - not specified }\end{array}$ & $\begin{array}{r}25(24) \\
48(66) \\
29(-)\end{array}$ & $\begin{array}{r}28(36) \\
49(64) \\
25(-)\end{array}$ & 0.865 & $\begin{array}{r}5(33) \\
10(77) \\
4(-)\end{array}$ & $\begin{array}{c}1(8) \\
11(92) \\
4(-)\end{array}$ & 0.182 \\
\hline $\begin{array}{l}\text { blood vessels invasion: } \\
\text { - yes } \\
\text { - no } \\
\text { - not specified }\end{array}$ & $\begin{array}{r}21(30) \\
49(70) \\
32(-)\end{array}$ & $\begin{array}{r}30(41) \\
43(59) \\
29(-)\end{array}$ & 0.221 & $\begin{array}{c}5(33) \\
10(77) \\
4(-)\end{array}$ & $\begin{array}{c}2(16) \\
10(84) \\
4(-)\end{array}$ & 0.408 \\
\hline
\end{tabular}

GRM - gentamicin-collagen sponge; LAR - low anterior resection; AR - anterior resection; ASAR - abdominosacral amputation of the rectum; Hrtm. - Hartmann procedure 
RR 2.75; 95\% Cl: 0.90-8.33). The use of GRM in operated patients within a short interval after the end of radiotherapy (group A) was connected with a lower rate of metachronic distant metastases ( $13.7 \%$ vs. 33.3\%; $p=0.002 ; \mathrm{RR} 0.41 ; 95 \% \mathrm{Cl}$ : 0.24-0.72). No similar relationship was observed in the case of surgery performed after a longer interval ( $p=1.000$; RR 1.68; 95\% Cl: 0.17-16.91).

Irrespective of the length of the interval between the end of radiotherapy and surgery, the application of GRM did not affect the rate of 5-year overall survival (group $A: p=0.484$; HR 1.20; 95\% Cl: 0.72-1,99; group B: $p=0.956$; HR 1.04; 95\% Cl: 0.23-4.66) (fig. 2).

The use of GRM improved the 5-year disease free survival rate, but only in cases when the surgery was performed within 7 days of the completion of radiotherapy ( $p=0.008$ HR 2.16; $95 \% \mathrm{Cl}$ [1.20-3.83] vs. $\mathrm{p}=0.892 \mathrm{HR} 1.11 ; 95 \% \mathrm{Cl}$ [0.25-4.96]) (fig. 3).

The analysis of 5-year cancer specific survival shows an improvement in results in the case of surgery performed after a short interval (group A) and the intraoperative use of GRM ( $p=0.010$; HR 2.37; 95\% Cl: 1.20-4.67 vs. $p=0.820$; HR 0.80; 95\% Cl: 0.11-5.66) (fig. 4).

\section{Discussion}

Long-term results of the randomized study carried out by the Dutch Colorectal Cancer Group, showed that a short-lasting radiotherapy with high fractionated doses connected with immediate TME radical resection, decrease the risk of local re-

a) group $A$

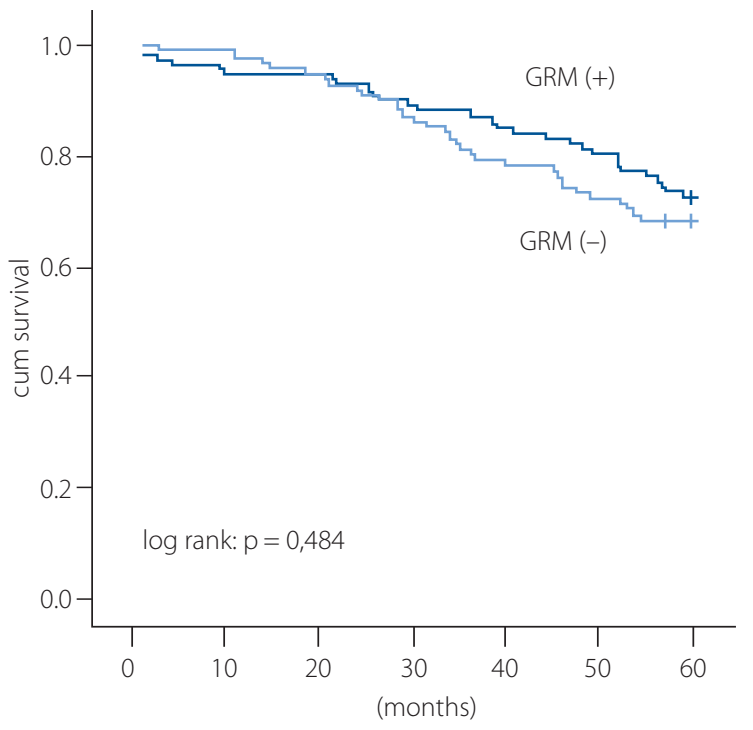

$\begin{array}{cccccccc}\text { GRM (+) } & 102 & 97 & 96 & 90 & 86 & 82 & 74 \\ \text { GRM (-) } & 102 & 100 & 96 & 88 & 80 & 74 & 70\end{array}$

GRM (+): patient group with the use of the gentamicin-collagen sponge GRM (-): patient group without the use of the gentamicin-collagen sponge currence of rectal cancer. This, however, does not translate into a prolongation of overall survival [5]. Some studies suggested that the prolongation of the interval between the radiotherapy and surgery by $>4$ weeks in patients suffering from resectable rectal cancer in stage $\mathrm{CT} 3 \mathrm{~N}+$, increases the rate of complete pathological remissions and overall survival [6].

The Stockholm III study has proven that a delay of surgery by $6-8$ weeks after a short-lasting brachytherapy, increases the rate of clinical remissions, but does not affect the prolongation of overall survival [7]. Two randomized studies which were carried out concerning the effect of the intraoperative use of GRM on the results of the treatment of patients with rectal cancer, showed a significant decrease in the risk of distant metastases, but the mechanism of anti-cancer action of the agent remained unknown [1, 2].

The objective of the current retrospective studies, based on the materials from the two randomized studies, was to explain whether the length of the interval between the completion of hyper-fractionated short-term preoperative radiotherapy had any effect on the obtained oncological results. Each time, the prolongation of the interval was only the result of the medical contraindications for the surgery performed immediately after the completion of radiotherapy. Therefore, the difference in the numbers of the two compared groups was so high (group A: 204 patients vs. group B: 35 patients). In those patients with a delayed surgery, the disease stage as evaluated preoperatively (ypTNM) was lower ( $p=0.005)$ - this is shown in table I. The explanation for this may be the pathomorphological remission b) group B

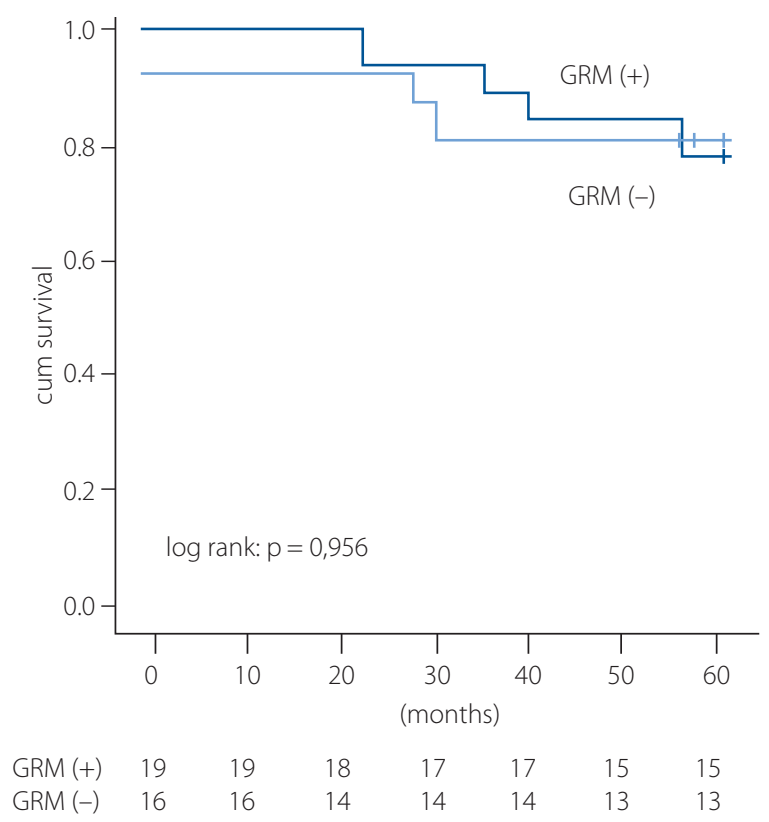

Figure 2. 5-year overall survival 
a) group $A$

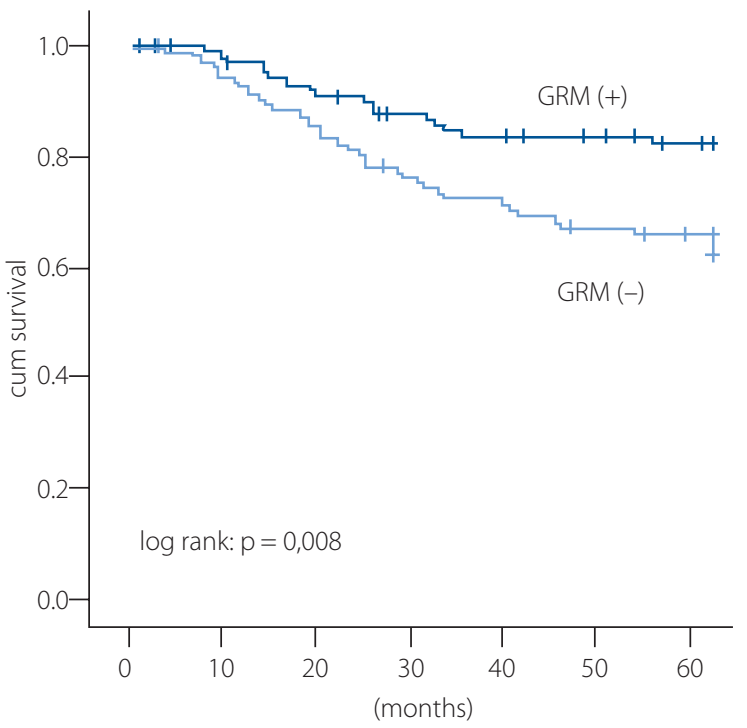

$\begin{array}{llllllll}\text { GRM (+) } & 102 & 99 & 93 & 89 & 86 & 86 & 85\end{array}$

$\begin{array}{llllllll}\text { GRM (-) } & 102 & 96 & 85 & 77 & 71 & 68 & 67\end{array}$

GRM (+): patient group with the use of the gentamicin-collagen sponge

GRM (-): patient group without the use of the gentamicin-collagen sponge

Figure 3. 5-year disease free survival period

a) group $A$

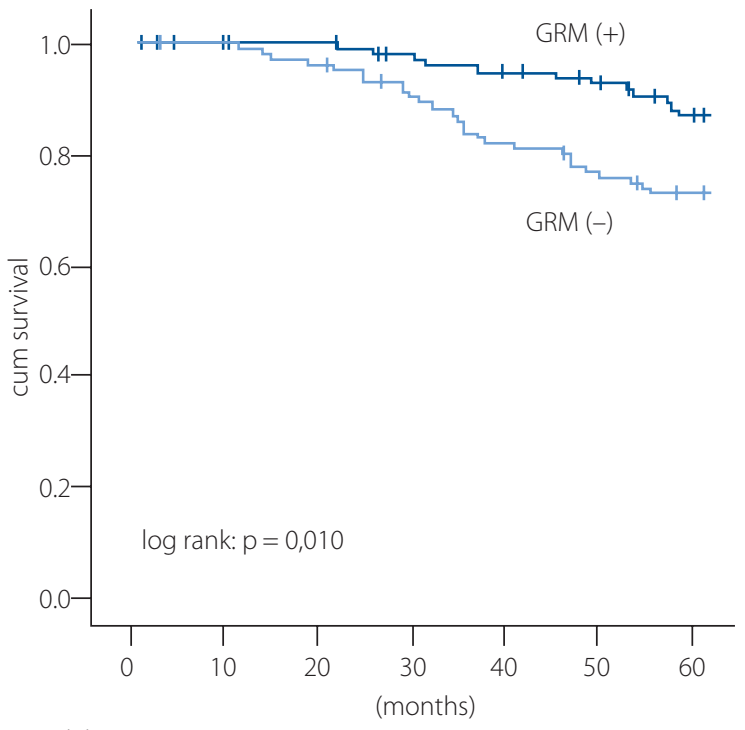

$\begin{array}{llllllll}\text { GRM (+) } & 102 & 102 & 102 & 98 & 97 & 94 & 90\end{array}$

$\begin{array}{llllllll}\text { GRM (-) } & 102 & 101 & 98 & 91 & 83 & 78 & 75\end{array}$

GRM (+): patient group with the use of the gentamicin-collagen sponge

GRM (-): patient group without the use of the gentamicin-collagen sponge

Figure 4. 5-year cancer specific survival period

of the cancer [8]. The use of GRM in patients operated on after a short break (group A) was connected with a lower rate of metachronic distant metastases (3.7\% vs. 33.3\%; $p=0.002$ ). No similar relationship was observed in group $B(p=1.000)$. b) group $B$

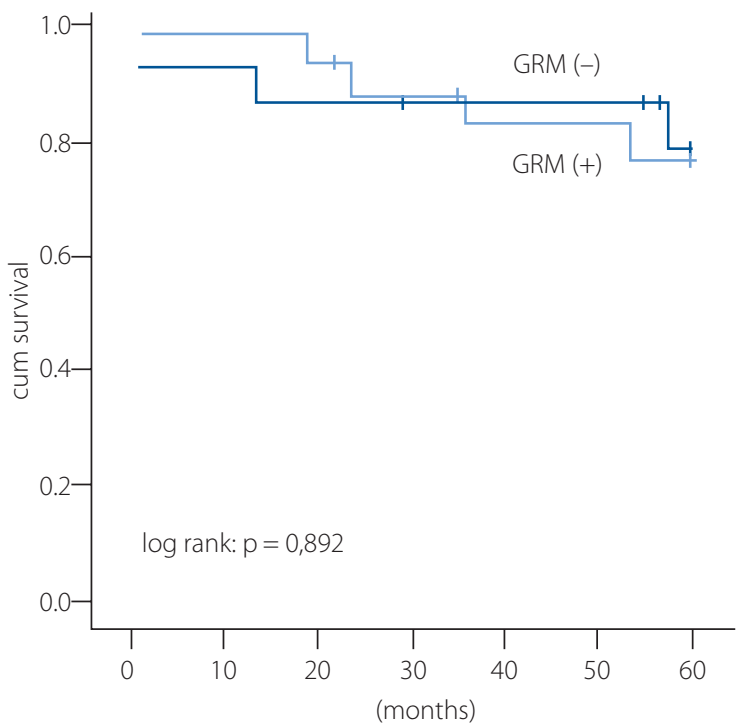

$\begin{array}{llllllll}\text { GRM (+) } & 19 & 19 & 18 & 17 & 17 & 15 & 15\end{array}$

b) group $B$

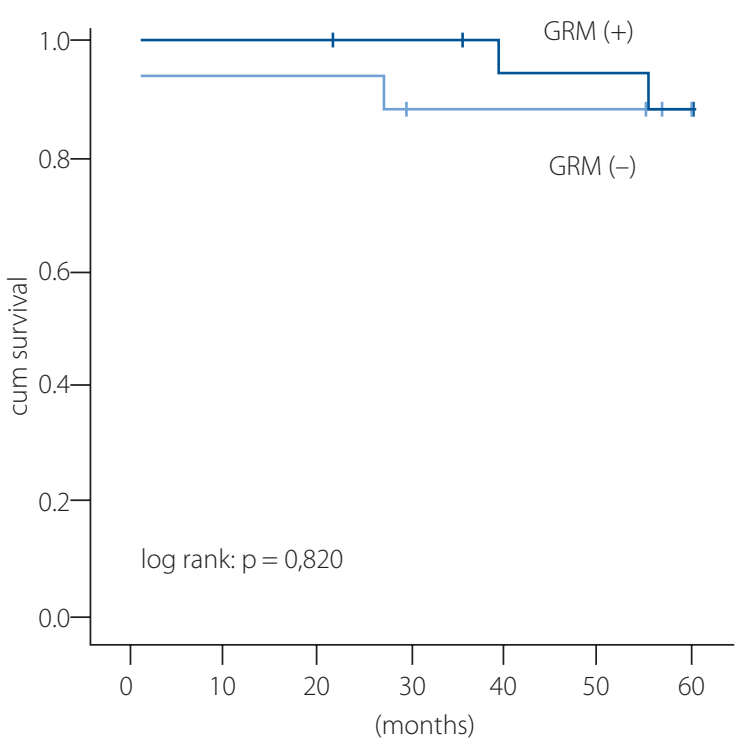

$\begin{array}{llllllll}\text { GRM (+) } & 19 & 19 & 19 & 19 & 18 & 17 & 17\end{array}$ $\begin{array}{llllllll}\text { GRM (-) } & 16 & 16 & 15 & 14 & 14 & 14 & 14\end{array}$

The improvement of the rate of 5-year disease free survival was seen solely in the case of the application of GRM in the patients operated on immediately after radiotherapy (group $A ; p=0.008$ ). This, however, did not affect the 5 -year overall 
survival. However, the analysis of cancer specific survival may suggest a beneficial anti-cancer effect of GRM, provided it is used during surgery performed immediately ( $\leq 7$ days) after the completion of irradiation.

In spite of these encouraging results, the mechanism of anti-cancer activity of GRM remains unknown. Moreover, the fact that the observed anti-cancer effect of the application of this agent is stronger in the case of surgery performed immediately after the end of irradiation, cannot be explained either. A postulated hypothesis may be the modulation of the developing inflammatory reaction in the irradiated area by means of locally acting antibiotics. There are data which support the activation of the immunological response after the use of short-term radiotherapy [9-11]. The damaged cells from the tissues undergoing irradiation and immunologically-inflammatory resident cells release factors which attract the cells from the blood and (or) lymphatic circulation [12, 13]. The effect of the immunological response to the applied radiotherapy may concern not only the irradiated tissues, but also distant ones, which is known as the abscopal effect [3, $14,15]$. The key factor here may be the fact that during the short break between the end of radiotherapy and surgery, a bactericidal, and also indirectly, anti-inflammatory agent is implanted into the area of the developing post-irradiation inflammatory reaction. As a result, this may affect the final shape of the immunological response, and thus, the obtained oncological results.

In spite of the fact that the material comes from randomized prospective studies, the results of the presented study must be interpreted with the utmost caution. This is the outcome, first of all, of the fact that the study was retrospective. The length of the interval was not the outcome of random selection, and the delay in surgery might have concerned patients in whose cases the prognosis of survival was poorer on account of their comorbidities. In a large proportion of patients (20-23\%), significant data was missing: the length of the resection margin, the invasion of blood and/or lymphatic vessels and the radicality of mesorectal resection were not analysed. Moreover, the disproportion in the numbers of the studied patient group, has significantly decreased the power of the sample. A small number of patients with a long interval between the end of radiotherapy and surgery does not allow for a definite conclusion whether the use of GRM affects the long-term oncological results.

To sum up, the study results may suggest that the intraoperative use of GRM is beneficial as it decreases the risk of distant metastases and the prolongation of disease free survival, first of all in situations when surgery is performed within a short period of time ( $\leq 7$ days) after the completion of irradiation. This, however, requires confirmation by a randomized and multi-centre clinical trial.

Conflict of interest: none declared

\section{Andrzej Rutkowski}

M. Sklodowska-Curie National Research Institute of Oncology Department of Oncological Gastroenterology

ul. Roentgena 5

02-781 Warsaw, Poland

e-mail:az.rutkowski@onet.eu

Received: 10 Dec 2020

Accepted: 19 Dec 2020

\section{References}

1. Nowacki MP, Rutkowski A, Oledzki J, et al. Prospective, randomized trial examining the role of gentamycin-containing collagen sponge in the reduction of postoperative morbidity in rectal cancer patients: early results and surprising outcome at 3-year follow-up. Int J Colorectal Dis. 2005; 20(2): 114-120, doi: 10.1007/s00384-004-0632-2, indexed in Pubmed: 15375668.

2. Rutkowski A, Pietrzak L, Kryński J, et al. The gentamicin-collagen implant and the risk of distant metastases of rectal cancer following short-course radiotherapy and curative resection: the long-term outcomes of a randomized study. Int J Colorectal Dis. 2018; 33(8): 1087-1096, doi: 10.1007/s00384-018-3045-3, indexed in Pubmed: 29656304.

3. Hanna GG, Coyle VM, Prise KM. Immune modulation in advanced radiotherapies:Targeting out-of-field effects. Cancer Lett. 2015; 368(2): 246251, doi: 10.1016/j.canlet.2015.04.007, indexed in Pubmed: 25892550.

4. Grass GD, Krishna N, Kim S. The immune mechanisms of abscopal effect in radiation therapy. Curr Probl Cancer. 2016; 40(1): 10-24, doi: 10.1016/j.currproblcancer.2015.10.003, indexed in Pubmed: 26612692.

5. Peeters KC, Marijnen CAM, Nagtegaal ID, et al. Dutch Colorectal Cancer Group. The TME trial after a median follow-up of 6 years: increased local control but no survival benefit in irradiated patients with resectable rectal carcinoma. Ann Surg. 2007; 246(5): 693-701, doi: 10.1097/01. sla.0000257358.56863.ce, indexed in Pubmed: 17968156.

6. Kaytan-Saglam E, Balik E, Saglam S, et al. Delayed versus immediate surgery following short-course neoadjuvant radiotherapy in resectable (T3N0/N+) rectal cancer. J Cancer Res Clin Oncol. 2017; 143(8): 15971603, doi: 10.1007/s00432-017-2406-6, indexed in Pubmed: 28374169.

7. Erlandsson J, Holm T, Pettersson D, et al. Optimal fractionation of preoperative radiotherapy and timing to surgery for rectal cancer (Stockholm III): a multicentre, randomised, non-blinded, phase 3, non-inferiority trial. Lancet Oncol. 2017; 18(3): 336-346, doi: 10.1016/ S1470-2045(17)30086-4, indexed in Pubmed: 28190762.

8. Pettersson $D$, Lörinc $E$, Holm $T$, et al. Tumour regression in the randomized Stockholm III Trial of radiotherapy regimens for rectal cancer. Br J Surg. 2015; 102(8): 972-8; discussion 978, doi: 10.1002/bjs.9811, indexed in Pubmed: 26095256.

9. Napolitano M, D'Alterio C, Cardone E, et al. Peripheral myeloid-derived suppressor and T regulatory PD-1 positive cells predict response to neoadjuvant short-course radiotherapy in rectal cancer patients. Oncotarget. 2015; 6(10): 8261-8270, doi: 10.18632/oncotarget.3014, indexed in Pubmed: 25823653.

10. Habets TH, Oth T, Houben AW, et al. Fractionated Radiotherapy with 3 x 8 Gy Induces Systemic Anti-Tumour Responses and Abscopal Tumour Inhibition without Modulating the Humoral Anti-Tumour Response. PLoS One. 2016; 11(7): e0159515, doi: 10.1371/journal.pone.0159515, indexed in Pubmed: 27427766.

11. Golden EB, Chhabra A, Chachoua A, et al. Local radiotherapy and granulocyte-macrophage colony-stimulating factor to generate abscopal responses in patients with metastatic solid tumours: a proof-of-principle trial. Lancet Oncol. 2015; 16(7): 795-803, doi: 10.1016/ S1470-2045(15)00054-6, indexed in Pubmed: 26095785.

12. Guipaud $O$, Jaillet $C$, Clément-Colmou K, et al. The importance of the vascular endothelial barrier in the immune-inflammatory response induced by radiotherapy. Br J Radiol. 2018; 91(1089): 20170762, doi: 10.1259/bjr.20170762, indexed in Pubmed: 29630386.

13. Jarosz-Biej M, Smolarczyk R, Cichoń T, et al. Tumor Microenvironment as A "Game Changer" in Cancer Radiotherapy. Int J Mol Sci. 2019; 20(13), doi: 10.3390/ijms20133212, indexed in Pubmed: 31261963.

14. Siva S, MacManus MP, Martin RF, et al. Abscopal effects of radiation therapy: a clinical review for the radiobiologist. Cancer Lett. 2015; 356(1): 82-90, doi: 10.1016/j.canlet.2013.09.018, indexed in Pubmed: 24125863.

15. Park B, Yee C, Lee KM. The effect of radiation on the immune response to cancers. Int J Mol Sci. 2014; 15(1): 927-943, doi: 10.3390/ijms15010927, indexed in Pubmed: 24434638. 